\section{Metodologias Ativas}

e Ensino de Língua

Estrangeira: Objetos de

Aprendizagem como recurso

didático no contexto da

Gamificação

Active Methodologies and Foreign Language Teaching:

Learning Objects as a didactic resource in the context of Gamification

\section{Mirella Mota Cavalcante da Silva (iD) 9}

mirellamota10@gmail.com

Universidade Federal do Ceará - UFC

\section{Pâmela Freitas Pereira Toassi (iD) 9}

pamelatoassi.ufc@gmail.com

Universidade Federal do Ceará - UFC

\section{Myrcea Santiago dos Santos Harvey (D) 9}

myrceaharvey@gmail.com

Universidade Estadual do Ceará - UECE

\section{Resumo}

Diante do cenário atual, as ferramentas tecnológicas têm-se destacado como importantes aliadas no ensino virtual. Assim, o presente artigo tem por objetivo investigar como as práticas docentes, em especial a de língua estrangeira (LE), podem concorrer às aplicações metodológicas inovadoras quando mediadas pelos recursos digitais, para propor sugestões didáticas que maximizem uma melhor autonomia do alunado. Logo, apresentando uma contextualização da relação entre as Tecnologias Digitais da Informação e Comunicação (TDICs) e o ensino de LE, apontamos os objetos de aprendizagem (OAs) como ferramentas acessíveis à integração de métodos inovadores, tendo por conta o contexto da gamificação. Sendo assim, sob a perspectiva construcionista de Papert (2008) e do viés das metodologias ativas de ensino de Filatro e Cavalcanti (2018), referenciamos o protagonismo do aluno à construção significativa da produção colaborativa do conhecimento. A metodologia desse artigo enfoca o levantamento bibliográfico de cunho qualitativo (CRESSWELL, 2010; YIN, 2016), para amparar as análises delineadas e a aplicação dos OAs. Em relação às observações registradas nesse estudo, verificam-se desafios ao manejo docente quanto à incorporação de softwares educativos e gamificação às aulas virtuais, apesar de destacarmos nos métodos ativos, uma estratégia ponte na relação ensino-aprendizagem. Contudo, depreendemos que a integração dos recursos digitais à conjuntura metodológica docente infere novas formas interativas de aprender, e, parece tangenciar o processamento intelectual do educando (FILATRO; CAVALCANTI, 2018). Por isso, sugerimos que pesquisas futuras investiguem a utilização de games em diferentes contextos, enfocando a aprendizagem de variados aspectos da LE.

\section{Linguagęm Foco}

Revista do Programa de Pós-Graduação em Linguística Aplicada da UECE

FLUXO DA SUBMISSÃO

Submissão do trabalho: $31 / 07 / 2020$ Aprovação do trabalho: 27/08/2020 Publicação do trabalho: 25/09/2020

\section{COMO CITAR}

DA SILVA, Mirella Mota Cavalcante; TOASSI, Pâmela Freitas Pereira; HARVEY, Myrcea Santiago dos Santos. Metodologias Ativas e Ensino de Língua Estrangeira: Objetos de Aprendizagem como recurso didático no contexto da Gamificação. Revista Linguagem em Foco, v.12, n.2, 2020. p. 227 - 247. Disponível em: https://revistas.uece.br/index.php/linguagememfoco/article/view/3732. 
Palavras-chave

Gamificação; objetos de aprendizagem; metodologias ativas; ensino de língua estrangeira.

\begin{abstract}
Given the current scenario, technological tools have stood out as important allies in virtual teaching. In this sense, the present article aims to investigate how teaching practices, especially the ones related to foreign language (FL), can concur for innovative methodological applications when mediated by digital resources, in order to provide suggestions that maximize better autonomy of students. Therefore, we present a contextualization regarding the relationship between Digital Technologies of Information and Communication (DTIC) and the teaching of FL, we point out learning objects (LOs) as accessible tools for the integration of innovative methods, in the context of gamification. From the theoretical perspective of Papert's constructionism (2008) and from the perspective of proposing active teaching methodologies by Filatro and Cavalcanti (2018), we highlight the importance of the student's role in the significant construction of collaborative knowledge production. The methodology of this article focuses on a qualitative bibliographic survey (CRESSWELL, 2010; YIN, 2016) to support the outlined analyzes and the application of LOs. It is observed that the incorporation of educational software and gamification into virtual classes constitutes a challenge, however, we highlight, in the active methods, a bridge strategy in the teaching-learning relationship. Nevertheless, we understand that the integration of digital resources to the teaching context infers new interactive ways of learning, and it seems to touch the intellectual processing of the student (FILATRO; CAVALCANTI, 2018). Therefore, we suggest future research to investigate the use of games in different contexts, focusing on diverse aspects of FL learning.
\end{abstract}

Keywords

Gamification; learning objects; active methodologies; foreign language teaching.

\title{
Introdução
}

Dentre as pragmáticas contextuais do cenário atual, no que diz respeito ao caráter pandêmico mundial, aponta-se a importância da crescente necessidade de adequação das metodologias das práticas docentes frente à sociedade tecnológica. Em vista disso, pondera-se que a demanda do ensino virtual tende a fortalecer a inserção de abordagens didáticas que contemplam a utilização das Tecnologias Digitais da Informação e Comunicação (TDICs), como recurso legítimo atrelado ao processo educativo.

Nesse sentido, a compreensão da usabilidade desses recursos digitais em consonância à prática docente se coloca como um tópico premente à agenda de professores e pesquisadores que se dedicam ao ensino e aprendizagem de línguas estrangeiras. Neste artigo, nos amparamos no uso das TDICs sob os pressupostos teóricos da perspectiva construcionista para aplicação metodológica, conforme Papert (2008) e na proposição de metodologias ativas, segundo Filatro e Cavalcanti (2018). Sendo assim, acreditamos que a necessidade do uso das TDICs no contexto didático atual pode promover aulas interativas em um ambiente, onde, geralmente, há escassez de recursos - as escolas de Educação Básica (HARVEY, 2009).

Logo, em consideração à conjuntura do cenário tecnológico, remete-se a 
proposição de aplicações didáticas inovadoras que possibilitem, ainda mais, uma dinâmica equivalente que vislumbre a qualidade na relação ensino e aprendizagem. Sendo assim, neste artigo trataremos da aplicabilidade de Objetos de Aprendizagem (OAs), no contexto da Gamificação, como instrumento sugestivo à prática docente configurada ao ensino virtual.

Tendenciando à sugestibilidade de aprimorar e inovar os métodos docentes, e, considerando uma realidade virtual de ensino, a aplicabilidade de OAs parece inferir, de forma qualitativa, à concorrência de estratégias processuais de aquisição do conhecimento, as quais estimulam as formas de aprender. Nesse sentido, torna-se necessário ponderar a importância de uma aprendizagem mais significativa, a qual releve o protagonismo do aluno nas situações contextuais.

Sobre isso, justificamos que a possibilidade de incorporação de estratagemas docentes ao cenário das TDICs em compelir às alternativas inovadoras de aprendizagem, repercutem a necessidade de estudos investigativos que pontuem a viabilidade dessas ferramentas como recursos aos métodos ativos. Nessa óptica, releva-se que as análises qualitativas da utilização de novas inserções à abrangência de metodologias didáticas, e, em especial, o ensino de língua estrangeira (LE), objeto de estudo desse artigo, fomentam a riqueza da usabilidade de recursos digitais, tais qual a aplicabilidade gerencial dos OAs.

Nesse sentido, buscamos nesse artigo, através de um levantamento bibliográfico, de cunho qualitativo, responder às seguintes perguntas (1) De que forma as práticas docentes em LE podem possibilitar aplicações didáticas inovadoras, quando mediadas pelos recursos tecnológicos? e (2) Em que aspectos as metodologias que configuram o protagonismo do alunado inferem ao desenvolvimento da aprendizagem de LE?

Assim, quanto à organização estrutural desse artigo, respeitamos a seguinte forma: a presente seção introdutória consiste na apresentação dos objetivos de pesquisa, bem como uma breve contextualização e justificativa evidenciando a premência da temática levantada. Na sequência temos a seção 1, onde discutimos a relação entre as tecnologias digitais e o ensino de língua estrangeira. Posteriormente, apresentaremos, na seção 3, a gamificação como uma estratégia didática para o ensino de língua estrangeira. Na sequência, apresentamos uma análise de artigos e observações pontuais significativas (seção 4). Por fim, nas considerações finais deste trabalho, sugerimos a utilização de objetos digitais, tomando por base uma abordagem de ensino cujo princípio seja o protagonismo do alunado. 


\section{As tecnologias digitais e o ensino de língua estrangeira}

Em referência ao cenário atual e aos impactos advindos do mundo digital no contexto da educação, observa-se que as influências expressivas das TDICs sob os meios comunicativos se tornaram ainda mais desejáveis, para contextualizar uma realidade de ensino mais abrangente e inserida às práticas docentes. Segundo Lima, Loureiro e Passos (2016), as mudanças que advêm com as TDICs são consideradas como uma revolução na execução de tarefas docentes. Nessa ótica, acredita-se nas possibilidades educativas promovidas pelo uso das TDICs, as quais podem contribuir para o desenvolvimento das habilidades relativas à aquisição da língua pelo educando.

Em relação ao ensino de LE nas escolas, temos ciência que sua funcionalidade desempenha um papel importante na formação intelectual dos educandos, à medida que os alunos têm a oportunidade de conhecer novas culturas e interagir sobre modos diversificados de interpretação da realidade. Conquanto, pode-se compreender, então, a linguagem como uma prática social inserida no mundo contextualizado, haja vista as possíveis interações percebidas ante o processo de ensino. Logo, tratando-se da docência de uma língua estrangeira (LE), considera-se que o uso consciente das ferramentas digitais, como um instrumental facilitador do processo de aquisição linguística, tenciona a promoção mais significativa do ensino à relativa equivalência da aprendizagem, na relação professor e aluno.

Nesse sentido, entende-se que ao profissional docente implica a interposição da aplicação de metodologias elaboradas, sob a perspectiva de um planejamento pedagógico inteligente, o qual repercuta as diretrizes do saber e dissemine as variedades de aprendizagem. Em consonância, o ensino de uma língua estrangeira (LE) requer uma prática correspondente à manifestação do processo de aquisição da linguagem pelo educando, mediante aplicações equivalentes e metodológicas em contexto.

Conforme Filatro e Cavalcanti (2018), a integração de metodologias ativas que baseiam a articulação interdisciplinar entre teoria e prática por meio da interação do aprendiz com o mundo, e, enfocam na produção colaborativa de conhecimentos, propicia destacar o protagonismo do alunado.

Portanto, considera-se a relevância das pragmáticas de ensino de LE em contemplar a elaboração perspicaz de métodos que favoreçam a contextualização da língua estudada, ao passo que evidencie no processo de aquisição linguís- 
tica, a funcionalidade usual dos mecanismos de aprendizagem. Sob este aspecto, aponta-se, então, a elaboração de um bom planejamento didático pelo docente, no tocante ao seu objeto de ensino, a fim de concorrer às perspectivas da progressão do conhecimento, conforme se lê nos Parâmetros Curriculares Nacionais $(\mathrm{PCN})$ :

Assim, caracterizar o objeto de ensino significa caracterizar os conhecimentos e os usos que as pessoas fazem deles ao agirem na sociedade. Portanto, ao ensinar uma língua estrangeira, é essencial uma compreensão teórica do que é a linguagem, tanto do ponto de vista dos conhecimentos necessários para usá-la quanto em relação ao uso que fazem desses conhecimentos para construir significados no mundo social. (BRASIL, 1998, p.27)

Sendo assim, salienta-se, quanto ao profissional em LE, a importância em delimitar a compreensão do seu objeto de linguagem para uma prática metodológica concorrente aos níveis gradativos de aquisição e assimilação linguística pelo educando, possibilitando, assim, um desenvolvimento mais progressivo e desejável.

De acordo com Mellin (2000), o professor deve buscar motivar seus alunos, pois quando o aluno está incentivado para aprender alguma coisa específica seu comportamento é correto. Assim, acredita-se que entrelaçando-se a dinâmica coercitiva da relação contextual entre ensino e aprendizagem, mediante a atuação de uma prática docente consciente, os conhecimentos podem ser desenvolvidos, à medida que a construção equivalente dos significados seja palpável e vivenciada pelo aprendiz.

Nesse âmbito, a necessidade da prática docente em acompanhar as mudanças contextuais sociais, refletindo a importância da aplicação de uma abordagem de ensino inovadora e dinâmica que propicie uma aprendizagem relativa é imprescindível para a promoção de um ensino contextualizado e inerente ao cenário global. Em vista dessa relevância, observaram Lima e Loureiro (2015) que o docente precisa modificar sua postura diante do uso das TDICs em sala de aula, valorizando o protagonismo do discente em seu processo de aprendizagem. Logo, acredita-se que a aplicação de métodos ativos atrelados ao exercício laboral de um planejamento pedagógico direcionado à progressão da aprendizagem, parecem ser uma rica sugestibilidade didática. Conforme Moran (1999, p.2): 
a uma certeza provisória que dá lugar a novas descobertas e a novas sínteses (MORAN, 1999, p.2).

Nessa perspectiva, entende-se que a autenticidade da postura docente frente aos desafios de um cenário distinto pode cooperar para o aprimoramento de uma prática mais consciente, recheada de possibilidades inovadoras. Não obstante, a utilização de objetos digitais educacionais parece compor uma figuração exequível da promoção das relações interativas, para o desenvolvimento do conhecimento.

Apesar disso, haja vista a necessidade atual de uma adequação metodológica, em paralelo à motivação e capacitação dos docentes, quanto ao uso dos recursos tecnológicos, considera-se desafiador dinamizar o conteúdo didático nos ambientes virtuais durante as aulas de LE. Mesmo assim, reforça-se o encorajamento da aplicação de metodologias ativas que oportunizem uma aquisição linguística relativa, mediante um ensino contextualizado e inerente à conjuntura contemporânea.

Papert (2008), ao referir-se à utilização das tecnologias digitais associadas às práticas docentes, afirma existirem duas polaridades no eixo do conhecimento e ensino. De um lado tem-se o instrucionismo, que, mesmo com todo o aparato proporcionado pelas tecnologias, detém-se na ideia de repasse do conhecimento. E por outro lado, encontra-se o construcionismo, em que o aprendiz adquire suas experiências mediante a construção do conhecimento na relação estabelecida com o objeto de saber. Logo, o educando tem a oportunidade de interagir ativamente no processo de ensinar e aprender, de forma que o conhecimento seja construído significativamente, ao invés de ser apenas repassado.

Em consonância, Ausubel (1978, apud FERNANDES, 2011) afirma que o fator isolado mais importante que influencia o aprendizado é aquilo que o aprendiz já conhece. Nessa ótica, pensamos ser relevante atentar para os conhecimentos prévios que o educando já armazenou na direção de favorecer a aplicação de novos conteúdos, em associação à riqueza da utilização proporcionada pelo uso das tecnologias.

Assim, em vista às percepções construcionistas, compreende-se que a dinâmica na relação entre o ensino e aprendizagem tende a ser favorecida pela inserção de abordagens didáticas que desempenhem usabilidade funcional à aplicação teórica, mediadas pela utilização das TDICs. E, ainda, conforme Zannata (2012, p.01): "no processo de aprendizagem, à perspectiva construcionista, o aluno é o protagonista da construção do seu próprio conhecimento". Dessa maneira, as 
ferramentas digitais parecem oferecer ricas possibilidades quanto à qualidade de aprendizagem, haja vista o ensino virtual.

Portanto, no presente artigo enfatizamos a importância de metodologias inovadoras que concorram para a promoção qualitativa da assimilação e aquisição de LE, tendo como referência a concepção construcionista de Papert (2008) quanto à construção significativa do conhecimento pelo educando, no contexto da sociedade tecnológica. Nessa perspectiva, apresentamos na próxima seção a gamificação como proposta didática para o ensino de língua estrangeira.

\section{Metodologias ativas e gamificação como proposta didática para o ensino de língua estrangeira}

Primeiramente, é necessário compreendermos o que são as metodologias ativas que são metodologias que "focam papéis desempenhados no processo e as atividades realizadas por eles" (FILATRO; CAVALCANTI, 2018, p. 5). Ainda, ensinam as autoras, que as metodologias ativas possuem princípios essenciais, a saber: protagonismo discente, ensino colaborativo e reflexão e ação nas atividades (FILATRO; CAVALCANTI, 2018). Essas metodologias têm como elemento fundante a visão humanista, ou seja, as pessoas. Ainda, segundo Filatro e Cavalcanti (2018), trata-se de metodologias que podem ser aplicadas a vários contextos, tais como corporações e ambientes educacionais.

Filatro e Cavalcanti (2018) explicam com propriedade que as metodologias ativas fazem parte de um arcabouço maior chamado metodologias de ensino e aprendizagem, que foram contempladas numa pesquisa da Universidade de Harvard, que investigou quais eram as competências fundamentais para a população em geral, cidadãos ou profissionais, do século XXI (FILATRO; CAVALCANTI, 2018, p. 17). Como resultado, a lista em lume teve 9 resultados, dos quais destacamos: colaboração, curiosidade e imaginação e solução de problemas (FILATRO; CAVALCANTI, 2018).

Nesse sentido, podemos perceber que as competências destacadas no estudo acima citado estão imbricadas aos princípios das metodologias ativas. Com efeito, Filatro e Cavalcanti (2018) também apontam as abordagens teóricas e fundantes das metodologias em tela. São elas: a pedagogia, andragogia e heutagogia.

A primeira diz respeito ao ensino tradicional das crianças, também tradicionalmente usado para a educação de adultos. Já a andragogia, cujo precursor foi Malcolm Knowles, é considerado o termo correto para o ensino e educação 
de adultos. Por último, a heutagogia, termo que surgiu em 2002 por Kenyon e Hase, surgiu no contexto da era digital e diz respeito à autonomia dos sujeitos, como estes organizam seus estudos, decidem e gerenciam a sua aprendizagem (FILATRO; CAVALCANTI, 2018, p. 19). É importante frisar que a heutagogia é um princípio bastante presente nos estudos de educação à distância (EAD).

Sendo assim, a integração de ferramentas digitais às metodologias de ensino aponta para a incorporação de estratégias mais aplicáveis, as quais favoreçam a qualidade das relações interativas entre professor e aluno. Nessa ótica, os objetos de aprendizagem (OAs) ínsitos nas metodologias ativas e usados nas situações de microaprendizagem explanadas acima, aliado às práticas pedagógicas de uma língua estrangeira (LE), podem fornecer respostas às demandas na práxis docente, corroborando a premência dessa inovação no contextual educacional atual que suscita diariamente pesquisas e reflexividade docente sobre novas formas de ensinar e aprender. De fato, a reflexividade na prática docente (THERRIEN; THERRIEN, 2013), dentre as várias consequências positivas, é pertinente ao savoir-faire de um ensino significativo que engrandece a formação docente. De fato, os impactos advindos com as TDICs tendem a incrementar os métodos de ensino de maneira significativa. Segundo Moran (2017, p.1):

\begin{abstract}
As tecnologias digitais hoje são muitas, acessíveis, instantâneas e podem ser utilizadas para aprender em qualquer lugar, tempo e de múltiplas formas. O que faz a diferença não são os aplicativos, mas estarem nas mãos de educadores, gestores (e estudantes) com uma mente aberta e criativa, capaz de encantar, de fazer sonhar, de inspirar. Professores interessantes desenham atividades interessantes, gravam vídeos atraentes. Professores afetivos conseguem comunicar-se de forma acolhedora com seus estudantes através de qualquer aplicativo, plataforma ou rede social.
\end{abstract}

Desta feita, considera-se que a aplicação metodológica de ferramentas digitais num contexto de aprendizagem pode adicionar novas possibilidades didáticas às práticas docentes vigentes em LE, aumentando o leque de estratégias que podem dialogar com as novas metodologias ativas que ora apresentamos no presente artigo.

Tendo tudo isso em vista, a gamificação tem sido uma boa alternativa para representar inovação à prática docente. Conforme Alves (2014, p. 112) gamificação "não é jogo: é a utilização de mecânica, estética e pensamento, baseados em games para engajar pessoas, motivar a ação, promover a aprendizagem e resolver problemas". A autora ainda defende que a gamificação "como estratégia de aprendizagem é uma forma interativa e divertida para o alcance de um obje- 
tivo específico e mensurável" (ALVES, 2014, p. 132).

Segundo Filatro e Cavalcanti (2018), o termo gamificação foi cunhado pela primeira vez por Nick Pelling em 2002. No entanto, o termo somente ganhou atenção com a edição do livro A Realidade em Jogo, da autora Jane McGonical. Desde então, a gamificação ganhou o status de tática de mudança comportamental, objetivando conferir eficiência ao produto de ações de uma organização (FILATRO; CAVALCANTI, 2018, p. 162).

Enfatiza-se, então, que, as atividades direcionadas para a promoção do engajamento dinâmico entre docente e discente e/ou discente e discente, além de propiciar espaço interativo de aprendizagem podem estimular estrategicamente à construção dos significados, na qual o aluno é o protagonista durante o seu processo de aprendizagem. Alves $(2014$, p.24) afirma que "precisamos aprender com a tecnologia. É necessário que sejamos capazes de promover o mesmo engajamento que a tecnologia promove. $O$ aprendizado precisa ser mais rápido, interativo, engajador e por que não divertido?"

Dentre as ferramentas tecnológicas e educacionais inseridas no espaço da gamificação, selecionamos para este artigo, haja vista a exiguidade da escrita do presente, o Quizizz, o Kahoot!, o Socrative, o Duolingo e o Scribblenauts Unlimited como exemplos de games didáticos. As principais características desses recursos podem ser descritas abaixo, seguidos dos layouts ilustrados e retirados de seus links eletrônicos:

a) Quizizz (Figura 1): apresentando uma interface mais informal e divertida, como avatares, músicas e memes, a ferramenta configura "uma atividade de sala de aula divertida que permite a todos os alunos praticar juntos." (QUIZIZZ, 2018). Apesar de ainda não ser possível a incorporação de vídeos, mas a inserção de imagens e/ou áudios nas perguntas, e, permitir apenas a elaboração do formato múltipla escolha, esse recurso gratuito é uma boa opção para a execução de atividades dentro e fora de sala, oferecendo feedback aos alunos, além de funcionar em todos os dispositivos com navegador e uso prático em aparelhos móveis (tablets, smarthphones, android, laptops). Essa ferramenta digital possibilita, assim, como proposta de ensino gamificado, uma interação dinâmica na elaboração de questionários para as atividades didáticas, sugerindo uma aprendizagem à distância. (QUIZIZZ, 2020); 
Figura 1 - Aplicativo Quizizz

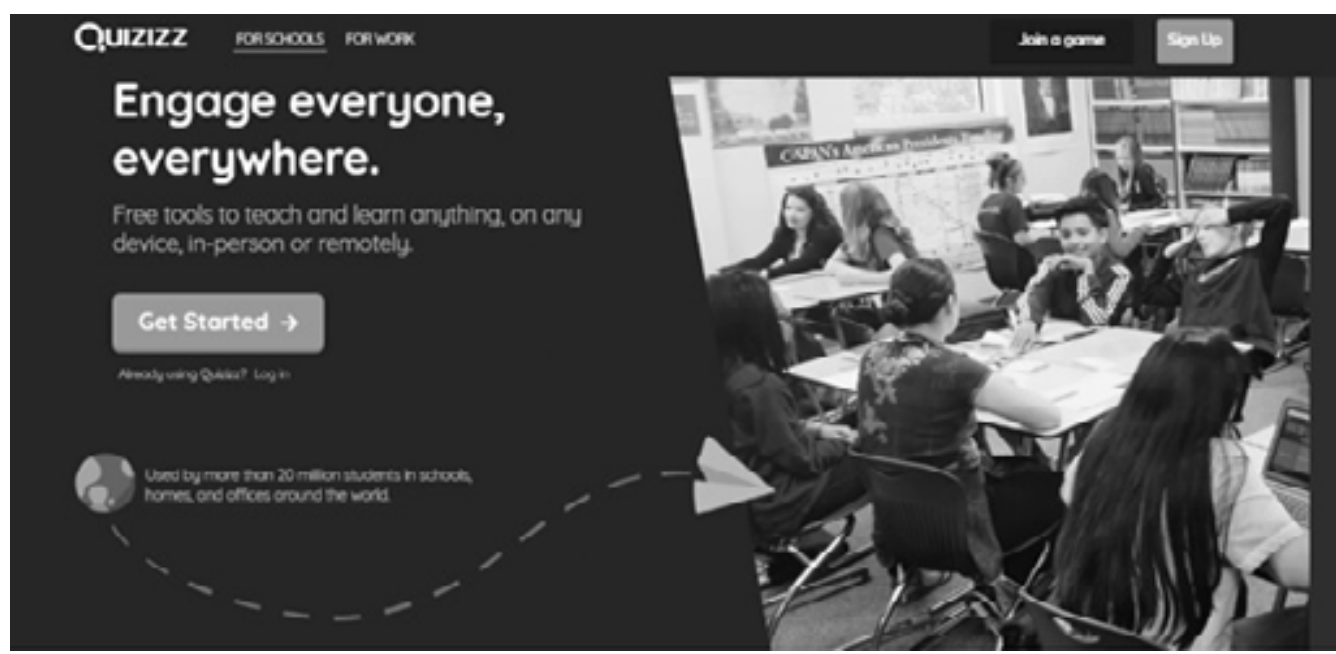

Fonte: (QUIZIZZ, 2020)

b) Kahoot! (Figura 2): define-se como "uma plataforma de aprendizagem gratuita baseada em jogos para professores e alunos" (KAHOOT!, 2018). Uma ferramenta interessante que permite a possibilidade de integrar jogos, com recursos como pesquisa, questionários, discussão e bagunça, apresentando também perguntas para mostrar os melhores jogadores do momento. Destaca-se pela possibilidade de incorporar vídeos, imagens e/ou diagramas nas perguntas, além de permitir um recurso desafio em que o professor pode atribuir jogos como tarefa de casa. Ademais, a plataforma propõe a possibilidade das instruções didáticas remotamente, para apresentação do conteúdo de uma maneira mais envolvente, preparando os alunos para os testes e aumentando a participação nas aulas (KAHOOT!2O2O);

Figura 2 - Aplicativo Kahoot

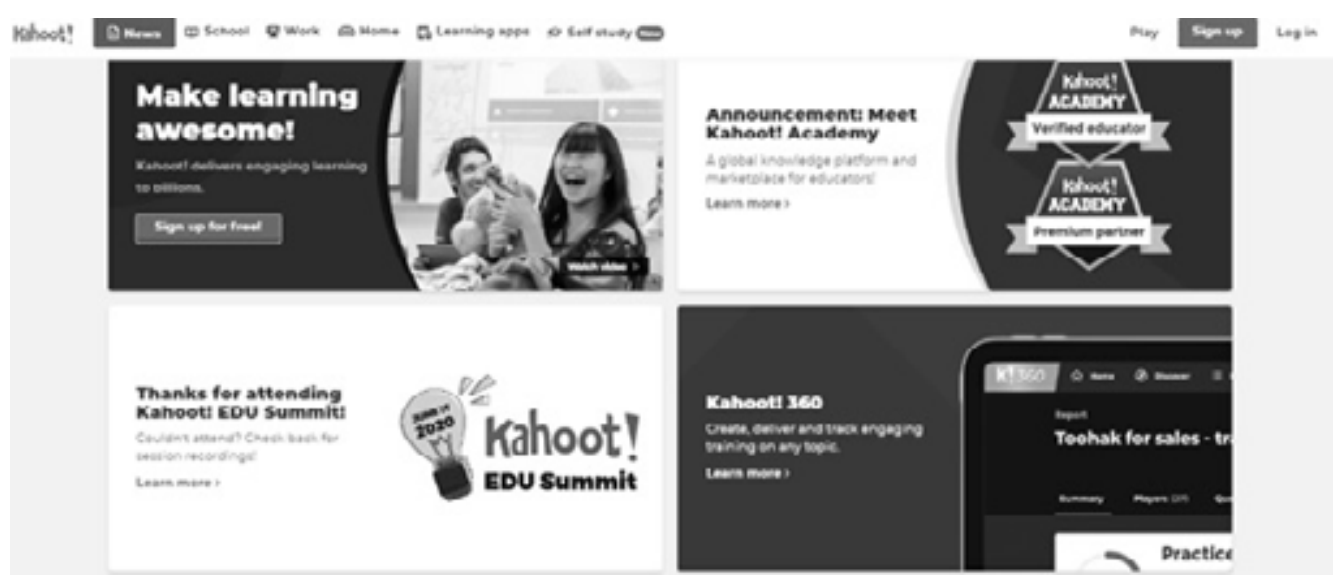

Fonte: (KAHOOT, 2020) 
c) Socrative (Figura 3): "uma ferramenta de resposta instantânea projetada para o Ensino Fundamental e Médio" (SOCRATIVE, 2018). Esse recurso possibilita aos professores a elaboração de questionários simples e a utilização em dispositivos variados. A plataforma sugere a visualização e acompanhamento dos alunos, de forma mais fácil, com engajamento eficaz e avaliações dinâmicas. (SOCRATIVE, 2020) É um ambiente acessível com feedback ao final da aula, possibilitando aos alunos observarem seus erros e acertos, assim como ao professor descobrir se os objetivos de ensino foram atingidos. Todavia, a ferramenta não permite incorporar vídeos e áudios nas atividades e não oportuniza tarefas extraclasses. Além disso, o recurso precisa ser custeado para utilização de uma versão mais sofisticada para abranger a capacidade de 150 alunos, em contraposição à gratuidade oferecida a uma turma de no máximo 50 alunos e com recursos mais limitados.

Figura 3 - Aplicativo Kahoot

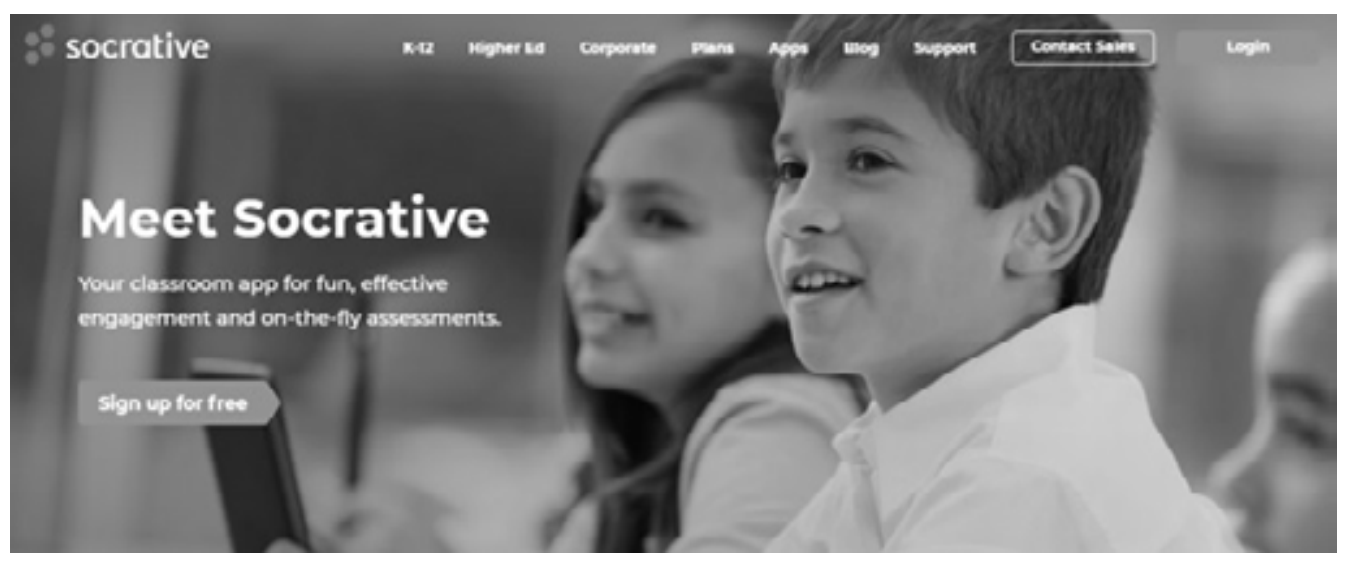

Fonte: (SOCRATIVE, 2020)

d) Duolingo (Figura 4): oferece opção de ensino de uma grande variedade de línguas estrangeiras em forma de jogo com fases e desafios. Além do uso individual do aplicativo como um instrumento de estudo, a plataforma do aplicativo oferece o 'Duolingo para escolas', no qual os professores podem monitorar a aprendizagem dos seus alunos. As atividades do aplicativo se baseiam em traduções da língua nativa para a língua alvo. São contempladas as habilidades de compreensão oral e escrita e de produção oral e escrita. A correção das atividades do aplicativo é disponibilizada de modo imediato, o que também é um ponto positivo para a aprendizagem e motivação do usuário. A sua versão gratuita oferece 
uma ampla possibilidade de utilização.

Figura 4 - $O$ aplicativo Duolingo

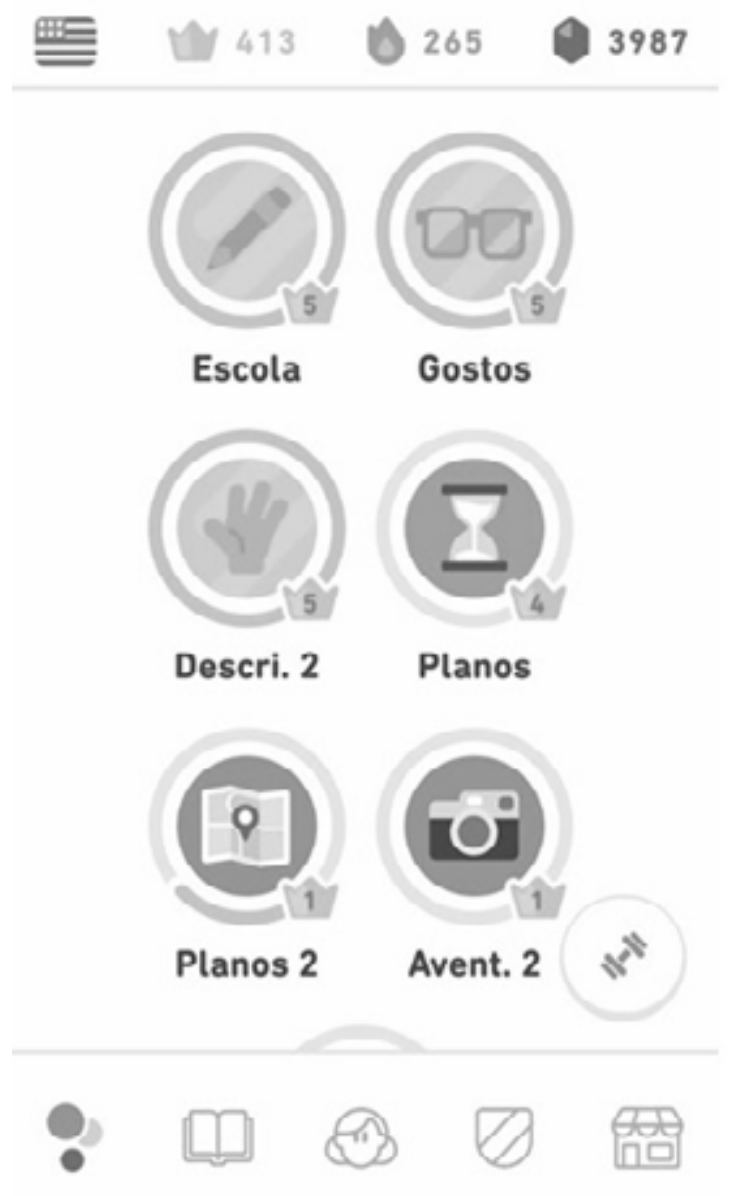

Fonte: Foto do aplicativo retirada do celular da autora.

e) Scribblenauts Unlimited (Figura 5): aliado na aquisição do vocabulário em língua inglesa, este jogo exige resolução de problemas através da escrita em inglês. Há neste jogo 25 mil palavras, e são reconhecidos tanto substantivos quanto adjetivos. De acordo com Silva e Toassi (2020, p. 267):

Os elementos apresentados no game incentivam a criatividade do jogador, pois é possível resolver os problemas apresentados com diferentes tipos de solução. Também ampliam o vocabulário do estudante, pois quando este se depara com uma situação em que é necessário invocar um objeto cujo nome em inglês não é conhecido, ele recorre ao dicionário. Em casos em que uma palavra tem mais de um significado, o jogo apresenta as opções de desambiguidade. Também, no caso de o jogador digitar uma palavra de forma equivocada, o jogo apresenta opções de palavras com escrita aproximada a que o jogador escreveu (SILVA; TOASSI, 2020, 
Figura 5 - Jogo Scribblenauts Unlimited

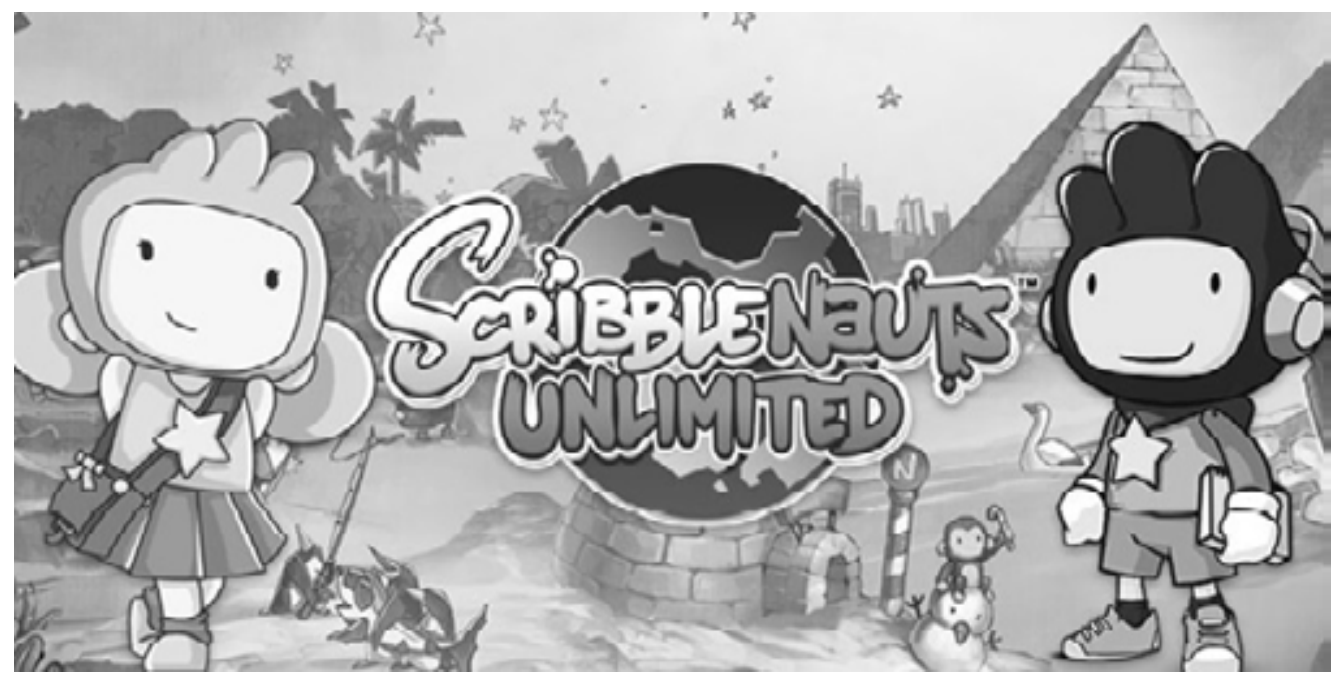

Fonte: Silva e Toassi (2020, p. 267)

Desse modo, os recursos apresentados acima parecem possibilitar práticas alternativas de interação, fomentando novas experiências de aprendizagem para os alunos (FILATRO; CAVALCANTI, 2018, p,183). Além do mais, os games acima representam estratégias docentes transformadoras, atendendo à demanda da geração Alpha, que são os nativos digitais. Em paralelo, a maior parte dessas ferramentas oferece opções de uso gratuito (com exceção do Scribblenauts Unlimited). Além disso, Quizizz, Kahoot!, Socrative e Duolingo oferecem a opção de o professor, através de uma conta individual, gerenciar as discussões e atividades elaboradas, recebendo feedback equivalente à participação dos alunos.

Logo, as estratégias interativas no contexto de ensino/aprendizagem de línguas, por meio do uso das metodologias ativas, podem ser concebidas como ferramentas didáticas potentes, conquanto a postura docente esteja suscetível à abertura de novas abordagens que se adaptem à realidade contextual do cenário global. Em outras palavras, o docente necessita de (uma formação acerca das tendências de aplicação de metodologias ativas, nas quais, o aluno é protagonista do seu processo de conhecimento (ALMEIDA et al, 2019). Nessa perspectiva, pondera-se, no que diz respeito ao docente em LE que:

As ajudas tecnológicas para o ensino de línguas existem há algum tempo, é claro, mas, em nossa opinião, a tecnologia atingiu um ponto em que deveria ser consid- 
erada não só como complemento do ensino ou como recurso para professores, mas também como uma oportunidade para aprendizagem autônoma. Uma abordagem tecnológica para o ensino das línguas baseia-se em um conjunto de princípios únicos, incluindo uma nova compreensão da natureza da linguagem (LARSENFREEMAN; ANDERSON, 2011, p. 17 apud SALES; SOUZA, 2018, p.35).

Sobre esse aspecto, consideramos que o delineamento da práxis do ensino de LE compreende a contemplação de uma formação sobre metodologias que favoreça a contextualização da língua ensinada, ao passo que evidencie, no processo de aquisição linguística, a funcionalidade usual dos mecanismos de aprendizagem, haja vista o princípio das metodologias imersivas e inovadoras (FILATRO; CAVALCANTI, 2018). Quanto a isso, pode-se observar na leitura dos PCN que "diferentemente do que ocorre em outras disciplinas do currículo, na aprendizagem de línguas o que se tem a aprender é também, imediatamente, o uso do conhecimento, ou seja, o que se aprende e o seu uso devem vir juntos no processo de ensinar e aprender línguas." (BRASIL, 1998, p.27).

No que diz respeito à mediação das tecnologias às práticas docentes, o fazer pedagógico per se já é uma tecnologia, e por isso, podemos entender que as metodologias ativas são instrumentos pedagógicos que podem possibilitar o trabalho interativo e desencadear vários outros objetivos educativos, mais significativos e até mais duradouros, possibilitando, assim, uma aprendizagem significativa, principalmente quando se trata de uma LE (TARDIF, 2014; FILATRO; CAVALCANTI, 2018).

Destarte, acreditamos ser oportuna, frente aos desafios da proposição de ensino virtual, uma sugestão didática que englobe a integração dos instrumentais digitais, os quais podem ser percebidos em atividades de gamificação, no contexto de aplicação. Não obstante, as ferramentas tecnológicas parecem ser esculpidas como recursos educacionais para dinamizar os métodos de ensino em LE, à medida que objetivam o melhor desenvolvimento interativo do conhecimento pelos estudantes, ao passo que a aquisição linguística vai se tornando evidenciada. Nesse contexto apresentamos alguns estudos que investigaram a relação entre TDICs e aprendizagem de LE.

\section{Análise de artigos}

A fim de averiguar a aplicabilidade e usabilidade dos instrumentos digitais durante a exposição das aulas, Silva (2018) aplicou um questionário aos docentes que utilizam recursos digitais em suas práticas laboriosas. O questionário 
foi destinado a um grupo de 29 docentes que já integram em suas metodologias, as tecnologias digitais como alternativas didáticas. As perguntas deste questionário coletaram informações relativas ao conhecimento e a compreensão dos docentes no tocante à utilização de objetos digitais, assim como às ferramentas de ensino tecnológicas percebidas na gamificação.

No estudo de Silva (2018), foi registrado que 75,9\% dos entrevistados já tinham ouvido falar do termo gamificação envolvendo a prática docente. Apenas $24,1 \%$ entendiam o significado de software de autoria para aplicação didática. Quanto à definição de gamificação, 89,7\% indicaram como sendo "games em contexto"; 62,1\% afirmaram conhecer objetos de aprendizagem (OAs), como o Quizizz, o Kahoot! e o Socrative; apenas, 24,1\% responderam que já utilizaram esses OAs. Dentre esses que utilizaram, $44,8 \%$ consideraram relevante suas utilizações, como ferramenta hábil em contexto de aprendizagem do aluno. Mesmo assim, 51,7\% apontaram esses objetos digitais como uma boa proposta didática ao exercício docente. Logo, esse estudo mostrou que, embora os recursos tecnológicos exerçam importância para dinamizar as atividades desenvolvidas em sala de aula, a gamificação parece ainda não ser prática difundida como proposição didática ao incremento de aulas motivadoras e interativas.

Silva e Toassi (2020) aplicaram um questionário a 46 pessoas, com idade média de 30 anos, sobre o uso de jogos eletrônicos e a aprendizagem de língua estrangeira. Os resultados coletados indicaram que $48 \%$ dos entrevistados afirmaram jogar vídeo games, destes, 59\% afirmaram utilizar, diariamente, jogos com interface em língua inglesa. Os participantes também mencionaram que a motivação de entender as instruções do jogo para seguir adiante os leva à ampliação do vocabulário na língua estrangeira. Outros aspectos de desenvolvimento da língua estrangeira mencionados, mas em menor percentual em relação ao do vocabulário, foram pronúncia, gramática e leitura. Outro dado relevante desta pesquisa foi que $80 \%$ dos participantes responderam que indicariam os jogos eletrônicos para a aprendizagem da língua inglesa.

A eficiência do aplicativo Duolingo como um instrumento auxiliar na aprendizagem da língua inglesa em turmas de escolas públicas na região de Fortaleza, Ceará foi investigada por dois estudos. O primeiro deles, de Sousa, Cardoso e Toassi (2018) teve como foco o uso do aplicativo na aprendizagem da habilidade escrita do vocabulário em inglês de alunos do $6^{\circ}$ ano. Os resultados do estudo mostraram que além de o aplicativo auxiliar na melhoria da habilidade escrita dos alunos e na aquisição de vocabulário em inglês, os alunos também se 
sentiram mais motivados para a aprendizagem da língua, utilizando-a também fora do ambiente escolar. Dessa forma, o estudo mostrou que instruir os alunos no uso de aplicativos pode ampliar o seu tempo de contato com a LE. O segundo estudo, de Sousa, Cardoso e Toassi (2019) foi realizado com alunos do $8^{\circ}$ ano para o desenvolvimento da habilidade oral da língua inglesa. Neste estudo, os resultados do grupo experimental e controle não mostraram uma diferença significativa em relação ao uso do aplicativo, porém, observou-se um aumento na motivação dos alunos que fizeram uso do aplicativo Duolingo.

Resumidamente, os resultados destes dois estudos sugerem que, embora, os ganhos linguísticos decorrentes da utilização do aplicativo possam não ser percebidos de imediato na habilidade oral, o fator interativo do aplicativo pode levar a uma motivação maior dos alunos em estudarem a língua estrangeira, o que pode gerar benefícios em longo prazo.

Huang e Chang (2016) investigaram o uso de dois aplicativos (Hastars e Memorizing vocabulary) para a aprendizagem de vocabulário em inglês por 10 dias. Participaram do estudo 30 estudantes universitários em Taiwan. Os resultados do uso dos aplicativos foram positivos para o aperfeiçoamento do conhecimento de vocabulário destes alunos, mesmo com o curto período de tempo empregado. Outro benefício do uso dos aplicativos demonstrado pelos estudantes, através de respostas a um questionário, foi um aumento na motivação e satisfação em relação à língua inglesa. De acordo com os pesquisadores, os aspectos visuais dos jogos são favoráveis na consolidação de novos termos lexicais na memória de longo prazo. Huang e Chang (2016) sugerem o uso desse tipo de aplicativo como um meio de aperfeiçoamento da aprendizagem de língua estrangeira.

Levando em consideração os resultados desses estudos, podemos verificar que os OAs são estratégias potentes ínsitas nas metodologias ativas. Entretanto, advogamos pela necessidade da formação docente no Ensino Básico quanto à temática de metodologias ativas e OAs no ensino de LE. Além disso, ressaltamos a possibilidade de inovação quanto à utilização de softwares educativos, assim como objetos de aprendizagem às práticas docentes, para a execução de métodos construtivos no cenário global.

\section{Considerações Finais}

Neste artigo nos propusemos a investigar as seguintes questões: (1) De que forma as práticas docentes em LE podem possibilitar aplicações didáticas 
inovadoras, quando mediadas pelos recursos tecnológicos? e (2) Em que aspectos as metodologias que configuram o protagonismo do alunado inferem ao desenvolvimento da aprendizagem de LE?

Em relação à primeira pergunta, a respeito da relação entre práticas docentes e utilização das Tecnologias Digitais da Informação e Comunicação (TDICs), em especial à docência em língua estrangeira (LE), observamos que a inserção dos recursos digitais ao auxílio da abordagem metodológica dos professores parece favorecer, de forma qualitativa, o processo de aprendizagem e aquisição linguística do educando. Compreendendo que, frente à sociedade digital que emerge no cenário global, torna-se imprescindivel a necessidade docente em aprimorar suas técnicas de ensino, registra-se que a interposição de métodos ativos abriga novas possibilidades para promoção de uma dinâmica interativa no contexto interno das aulas de LE.

Conquanto, a despeito da configuração de um ensino virtual na realidade atual apontar um ajuste à demanda do planejamento pedagógico, tangencia-se que as práticas docentes ampliem seus estratagemas, com vistas à formação cidadã e à eficiência dos níveis qualitativos escolares. Nesta ótica, salienta-se que a inserção de OAs em contexto de Gamificação parece contribuir, na relação ensino-aprendizagem, para o estímulo do desenvolvimento das habilidades do aluno, à medida que o gerenciamento da utilização dessas tecnologias viabilize as situações de aprendizagem, ou seja, desde que o educador saiba utilizar esse recurso tecnológico para fins proveitosos.

Quanto à segunda pergunta desse artigo (Em que aspectos as metodologias que configuram o protagonismo do alunado inferem ao desenvolvimento da aprendizagem de LE?), consideramos que o entrelace entre a abordagem de ensino e a metodologia aplicada indica uma maior suscetibilidade de propor uma dinâmica mais atrativa à construção dos significados, tendo em vista um processo de aprendizagem em que o aluno seja protagonista do seu desenvolvimento autônomo quanto à aquisição dos conhecimentos.

Levando em consideração o estudo de Silva (2018), evidencia-se que a gamificação parece ainda não ser prática difundida pelos docentes como um recurso instrumental didático. Nesse ponto, denotamos a atenção para relevar a importância da busca de novas estratégias de ensino, e, novamente, destacamos a postura docente em se ater ao incremento de ricas significações didáticas, apesar dos desafios e possíveis desdobramentos que surjam nesse percurso.

Em complemento, quanto aos possíveis aspectos que inferem ao prota- 
gonismo do alunado em ensino de LE, os estudos de Sousa, Cardoso e Toassi (2018, 2019) revelaram que o fator interativo do aplicativo Duolingo pode levar a uma motivação maior dos alunos em estudarem a língua estrangeira, gerando, assim, benefícios em longo prazo, no quesito da aquisição linguística e aprendizagem significativa. Além disso, na pesquisa de Huang e Chang (2016), a utilização dos aplicativos (Hastars e Memorizing vocabulary) para a aprendizagem de vocabulário em inglês, registra que os aspectos visuais dos jogos são favoráveis na consolidação de novos termos lexicais na memória de longo prazo, e, portanto, o uso desses tipos de aplicativos é sugestivo como um meio de aperfeiçoamento da aprendizagem de língua estrangeira.

Nesse ínterim, pôde-se observar, na análise desses estudos, a inferência da postura docente em facilitar as possibilidades de ensino que configurem o protagonismo do aluno, estimulando as habilidades desse aprendiz, ao passo que as estratégias aplicadas mesclem alternativas contextuais de progressão às formas de aprender. Por isso, refletimos que a relação docente e discente precisa ser desenvolvida sob a ótica da produção autônoma do educando.

Logo, partindo do pressuposto teórico construcionista, entendemos que as possibilidades para o ensino virtual integrado às metodologias ativas precisam ser inovadoras e tangentes ao aprendizado. Nesse sentido, reforçamos que o docente precisa inovar e "partir de onde o aluno está. Ajudá-lo a ir do concreto ao abstrato, do imediato para o contexto, do vivencial para o intelectual." (MORAN, 1999, p. 7). Elencando o aluno como protagonista de sua aprendizagem, o professor se torna um facilitador desse processo.

Em respeito a isso, acreditamos que a proposta de gamificação sugere uma alternativa inovadora às abordagens de um ensino contextualizado. Entretanto, reforçamos a necessidade de uma aplicação consciente quanto à elaboração do plano de aula do docente envolvido. Os OAs abordados nesse artigo, como o Quizizz, o Kahoot!, o Socrative, o Duolingo e o Scribblenauts Unlimited podem ser facilmente acessados e gerenciados para a elaboração dessas aulas contextualizadas, conforme o conteúdo.

Tratando-se do cenário pandêmico atual, propomos que, apesar dos desafios, o docente, em especial em LE, ouse enriquecer suas metodologias, de forma mais ativa, buscando estratégias legítimas à aplicabilidade, tais como os OAs no contexto de gamificação, oportunizando, assim, o protagonismo do alunado em seu processo de aprender. Sendo assim, indicamos o Quizizz, o Kahoot!, o Socrative, o Duolingo e o Scribblenauts Unlimited como ferramentas tecnológicas 
disponíveis à testagem e execução da elaboração de aulas diferenciadas, a fim de propiciar uma aplicação prática e interativa no contexto de ensino virtual.

Assim, com base nos dados dos estudos revisados neste artigo, no que se refere aos aplicativos digitais de games para LE, instigamos aos envolvidos às tecnologias educacionais, a importância contínua da atualização dos softwares educativos, para fins de aplicação didática, já que se constata que o uso de games em contexto contribui para uma melhor motivação do aluno no seu processo de aquisição linguística. Adicionalmente, sugerimos a continuidade de investigações futuras quanto a aplicabilidade usual de gamificação em diferentes contextos, com foco na aprendizagem em distintos aspectos linguísticos.

\section{Referências}

AlMEIDA, A. C. A.; MELO, C. I. B.; HARVEY, M. S. S.; LIMA, M. V. A.; CHAVES, P. J. S. Metodologias Ativas à Luz de Comenius: uma Experiência na Pós-Graduação. In: CONGRESSO SOBRE TECNOLOGIAS NA EDUCAÇÃO (CTRL+E), 4, 2019, Recife. Anais do IV Congresso sobre Tecnologias na Educação. Porto Alegre: Sociedade Brasileira de Computação, dez. 2019, p. 60-68. DOI: https:// doi.org/10.5753/ctrle.2019.8876.

\section{ALVES, F. Gamification: como criar experiências de aprendizagem engajadoras: um guia} completo: do conceito à prática. 2 ed. São Paulo: DVS Editora, 2014.

BRASIL. Lei de Diretrizes e Bases da Educação Nacional. Lei n. ${ }^{\circ}$ 9.394/96, de 20 de dezembro de 1996. Disponível em: http://www.planalto.gov.br/ccivil_03/Leis/L9394.htm. Acesso em jun. 2020.

BRASIL. Secretaria de Educação Fundamental. Parâmetros curriculares nacionais: terceiro e quarto ciclos do ensino fundamental: língua estrangeira / Secretaria de Educação Fundamental. Brasília: MEC/SEF, 1998, 120 p.

CRESWELL, J. Projeto de Pesquisa: Métodos qualitativo, quantitativo e misto. Editora Sage, 2010.

FERNANDES, E. A ponte para Aprender. Nova Escola, edição 248, 2011.

FILATRO A., CAVALCANTI, C. Metodologias Inov-Ativas na Educação presencial, a distância e corporativa. São Paulo: Saraiva, 2018.

HARVEY, M. S. dos S. O Uso Didatico do Genero Filme Legendado na Aprendizagem de Leitura de Textos do Genero Jornalistico. 2009. Sem Numeração Dissertação (Mestrado Acadêmico ou Profissional em XX) - Universidade Estadual do Ceará, 2009. Disponível em: http://siduece. uece.br/siduece/trabalhoAcademicoPublico.jsf?id=57530. Acesso em: 31 jul. 2020

HUANG, Y.; CHANG, D. Fuzzy detecting the effect of mobile game-based learning for university students. TOJET: The Turkish Online Journal of Educational Technology, nov. 2016, Special Issue, pp. $1070-1080$.

KAHOOT!. Disponível em: https://kahoot.com/. Acesso em 28 jul. 2020.

LIMA, L.; LOUREIRO, R. Integração entre Tecnologias Digitais e Docência: A compreensão de grupos Interdisciplinares. In: XII EDUCERE Congresso Nacional de Educação. PUCPR, 2015, 
p.33313.

LIMA, L.; L..; PASSOS, C. A interdisciplinaridade na formação docente: Experiências convergentes do PIBID e da Tecnodocência. ENDIPE, 2016. Disponível em: http://www.ufmt.br/endipe2016/paineis-2408/. Acesso em: 13 abr. 2020.

MELLIN, C. Aprendendo a Ensinar. Ed. Quadrangular, $3^{\circ}$ ed. SP, 2000.

MORAN, J. M. O uso das Novas Tecnologias da Informação e da Comunicação na EAD: uma leitura crítica dos meios. Palestra realizada pela COPEAD/SEED/MEC em Belo Horizonte e Fortaleza, no ano de 1999. Disponível em: http://portal.mec.gov.br/seed/arquivos/pdf/T6\%20TextoMoran.pdf. Acesso em 20 jul. 2020.

MORAN, J.M. Tecnologias Digitais para uma aprendizagem ativa e inovadora. 2017. Disponível em: http://www2.eca.usp.br/moran/wpcontent/uploads/2017/11/tecnologias_moran.pdf. Acesso em 29 de jun. 2020.

PAPERT, S. A máquina das crianças: repensando a escola na era da informática. Porto Alegre: Artmed, 2008, 216p.

QUIZIZZ. Disponível em: < https://quizizz.com/>. Acesso em Jul. 2020.

SALES, J. T. L.; SOUZA, K. F. de. O Ensino de Gramática em Língua Inglesa. 1_ed. Fortaleza: EdUece, 2018.

SILVA, M. M. C. da. Tecnologia digital e língua inglesa: gamificação como proposta didática na perspectiva do construcionismo. 2018. 53 f. Trabalho de Conclusão de Curso (Especialização em Ensino de Língua Inglesa) - Universidade Estadual do Ceará, Fortaleza, 2018. Disponível em: http://siduece.uece.br/siduece/trabalhoAcademicoPublico.jsf?id=89132. Acesso em: 28 jul. 2020.

SILVA, F. W. da C.; TOASSI, P. F. P. O papel dos jogos eletrônicos na aquisição da língua inglesa. Revista do GEL, v. 17, n. 1, p. 259-283, 2020. Disponível em: https://revistas.gel.org.br/rg/article/ view/2757. Acesso em: 28 jul. 2020.

SOCRATIVE. Disponível em: < https://www.socrative.com/>. Acesso em Jul. de 2020.

SOUSA, G. M. B.; CARDOSO, L. A. B.; TOASSI, P. F. P. Duolingo as a tool to improve vocabulary writing in English as a foreign language. Letras em Revista, v.9, p.119 - 134, 2018. Disponível em: https://ojs.uespi.br/index.php/ler/article/view/199. Acesso em: 28 jul. 2020.

SOUSA, G. M. B.; CARDOSO, L. A. B.; TOASSI, P. F. P. Duolingo como ferramenta para o desenvolvimento das habilidades escrita e oral de vocabulário na Língua Inglesa. Comunicação oral. Semana Internacional de Letras da UNILAB, 2019. UNILAB, Redenção - CE.

THERRIEN, J.; THERRIEN, S. A integração das práticas de pesquisa e de ensino e a formação do profissional reflexivo. Educação. Santa Maria, v. 38, p. 619-630, 2013.

TARDIF, M. Saberes docentes e formação profisssional. 17 Edição- Petrópolis, RJ. Editora Vozes, 2014.

YIN, R. Pesquisa Qualitativa do início ao fim. Editora Penso. Porto Alegre, 2016.

ZANATTA, R.P.P. Análise de uma Abordagem Construcionista no processo ensino-aprendizagem de conceitos físicos e matemáticos com o uso da Robótica Educacional. In: II MOSTRA NACIONAL DE ROBÓTICA (MNR), 2012, Curitiba (PR). Anais (UTFPR). ISBN:978-85-64992-23-8. 


\section{Sobre os autores}

Mirella Mota Cavalcante da Silva - Mestranda do Programa de Pós Gradução em Estudos da Tradução (POET); Universidade Federal do Ceará (UFC); Fortaleza-CE; E-mail: mirellamota10@gmail.com. Lattes: http://lattes.cnpq.br/0304871209442655; OrclD: https://orcid.org/0000-0003-3261-881X.

Pâmela Freitas Pereira Toassi - Doutora em Estudos Linguísticos. Professora do Programa de Pós-Graduação em Estudos da Tradução (POET) da Universidade Federal do Ceará (UFC); Fortaleza-CE. Email: pamelatoassi.ufc@gmail.com. Lattes: http://lattes. cnpq.br/9588059820830584. OrcID: https://orcid.org/0000-0003-3273-639X

Myrcea Santiago dos Santos Harvey - Doutoranda do Programa de Pós-Graduação em Educação (PPGE) da Universidade Estadual do Ceará (UECE); Fortaleza-CE; Email: myrceaharvey@gmail.com. Lattes: http://lattes.cnpq.br/1668604497088494. ORCID: https://orcid.org/0000-0003-3973-9446 